This is an Open Access article licensed under the terms of the Creative Commons AttributionNonCommercial-NoDerivs 3.0 License (www.karger.com/OA-license), applicable to the online version of the article only. Distribution for non-commercial purposes only.

\title{
Factors Associated with Cognitive Decline in Elderly Diabetics
}

\author{
Hiroyuki Umegaki ${ }^{a}$ Takahiko Kawamura $^{b}$ Naoko Kawano ${ }^{a}$ \\ Toshitaka Umemurac ${ }^{c}$ Akio Kanai $^{b}$ Takahisa Sano $^{\text {b }}$ \\ ${ }^{a}$ Department of Geriatrics, Nagoya University Graduate School of Medicine, and \\ Departments of ${ }^{b}$ Metabolism and Endocrine Internal Medicine, and ${ }^{\mathrm{c}}$ Neurology, \\ Chubu Rosai Hospital, Nagoya, Japan
}

\section{Key Words}

Diabetes mellitus $\cdot \mathrm{HbA1C} \cdot$ Insulin $\cdot$ Neuropsychological tests $\cdot$ Prospective study

\begin{abstract}
Background/Aims: Although recent evidence has indicated that type 2 diabetes mellitus (T2DM) in the elderly is a risk factor for cognitive dysfunction or dementia, few studies have prospectively observed this potential cognitive decline. In the current study, we performed cognitive assessments at baseline and after 3 years in the same patient group in an attempt to reveal the contributions of diabetes-related factors to the increased decline in cognitive function in elderly patients with T2DM. Methods: We recruited 55 consecutive T2DM patients with a Mini-Mental State Examination (MMSE) score $\geq 24$ from the Diabetic Center at the Chubu Rosai Hospital. These patients ranged in age from 65 to 85 years. Cognitive and clinical assessments, including brain MRI, were performed at baseline and at the 3-year follow-up. Results: The higher plasma insulin and $\mathrm{HbA}_{1 c}$ levels observed at baseline were significantly associated with a worse cognitive performance at baseline and a more neurocognitive decline at the follow-up visit. Conclusion: The current prospective study suggests that higher insulin and glycohemoglobin levels may be associated with diabetes-related cognitive dysfunction.
\end{abstract}

Copyright $\odot 2011$ S. Karger AG, Basel

\section{Introduction}

Recent evidence has indicated that type 2 diabetes mellitus (T2DM) in the elderly is a risk factor for cognitive dysfunction or dementia [1]. Although several mechanisms have been proposed, the precise mechanisms that underlie T2DM-related cognitive dysfunction or the development of dementia have not yet been elucidated [2]. 
High glucose concentrations, a major pathological characteristic of diabetes, may have toxic effects on neurons in the brain through osmotic insults and oxidative stress [3]. Chronically high glucose also leads to enhanced formation of advanced glycation end products, which have potentially toxic effects on neurons [4].

T2DM, especially in conjunction with obesity, is characterized by insulin resistance and/ or hyperinsulinemia. Insulin resistance is defined as an inadequate response of target tissues (e.g. skeletal muscle, liver, and adipose tissue) to circulating insulin, and this condition is often accompanied by elevated insulin levels. Insulin is transported across the blood-brain barrier via an active transport mechanism into the central nervous system (CNS) [5] and is assumed to exert several effects on synapses and neurons. Furthermore, insulin resistance may also occur in the CNS [6]. Several studies have reported that hyperinsulinemia or insulin resistance is associated with cognitive dysfunction or dementia [7-10].

Small vessel disease in the brain (white matter lesions and lacunae) is frequently associated with T2DM. Although there is general consensus regarding the negative impact of large vascular lesions on cognition, the role that small vessel disease plays in cognitive dysfunction remains unclear. We have previously reported that small vessel diseases affect cognitive function in older diabetics without overt dementia or symptomatic stroke [11].

Although several factors have been hypothesized to contribute to diabetes-related cognitive dysfunction, available data are mainly from a cross-sectional analysis [12]. In several prospective studies, the presence of diabetes has been reported to affect cognitive function [12], but few prospective studies have investigated the effect of specific diabetes-related factors $[13,14]$. In two studies, results of the impact of glucose control levels measured by glycohemoglobin on cognitive function were inconsistent, but there have been no reports on the effects of insulin levels on cognitive function in diabetics based on prospective studies. In this study, we performed cognitive assessments at baseline and 3 years later in the same patient group. We examined the contribution of vascular and diabetes-related factors at baseline to the decline in cognitive function in elderly patients with T2DM.

\section{Methods}

\section{Patients}

We consecutively recruited 58 patients with T2DM [15] from the Diabetic Center at the Chubu Rosai Hospital. These patients ranged in age from 65 to 85 years. The exclusion criteria were as follows: a history of symptomatic stroke, malignancy, inflammatory disease, severe microvascular complications (such as renal failure), and severe cardiovascular disease (such as myocardial infarction and unstable angina). None of the patients exhibited audiovisual deficiencies that would prevent them from participating in cognitive function tests. The Mini-Mental State Examination (MMSE) scores of these patients were 24 and above at baseline.

An ethical committee approved the study, and all of the study patients provided their written informed consent prior to the investigation. After giving informed consent, patients were individually administered the cognitive function tests both at baseline (from April to June 2006) and at the 3-year follow-up (from April to May 2009). On the day of assessment, the patients had breakfast as usual, and the test was performed in the morning. Prior to the assessment, doctors performed a general physical checkup on the patients. Three of 58 patients did not participate in the follow-up assessment ( 2 female patients moved out of town and 1 male patient died from lung cancer). A total of 55 patients were analyzed in the current study. 


\section{Cognitive Tests}

Cognitive function was assessed via the following structured performance tests, which were selected to cover a broad range of cognitive domains, including (i) mental status, (ii) verbal memory, (iii) complex psychomotor skills, and (iv) attention/executive function. Mental status was evaluated using the MMSE [16], which is an assessment of general cognition. Verbal memory was tested with word recall using a word list, which is a subtest of the Alzheimer's Disease Assessment Scale [17]. Immediately after the word list of 10 common nouns had been read, the respondents were asked to repeat as many words as they could recall in any order (immediate). After approximately $30 \mathrm{~min}$ of interference tasks, the respondents were asked to recall the 10-word list again (delayed). In the current analysis, the number of words repeated in the delayed recall was used as an explanatory variable. Complex psychomotor skills were examined using the Digit Symbol Substitution (DSS) test, which is a subtest of the Wechsler Adult Intelligence Scale-Revised [18] and has a score range of 0-93. Attention/executive function was assessed with the Stroop Color Word test (Stroop; Japanese version) [19]. In this test, the amount of time (in seconds) required for the completion of a specific task is recorded. Specifically, the difference between the time required to read a word card versus the time required to read a dot card is calculated as an index of cognitive response conflict. A larger time interval is interpreted as a more cognitive response conflict by interference in performance. Well-trained psychologist examiners administered all four tests in the same order to all the study patients. Depression was assessed by the Geriatric Depression Scale-15 (GDS-15) [20], which is a global test of depression with scores ranging from 0 to 15 .

\section{Evaluation of the Patients}

Hemoglobin $\mathrm{A}_{1 \mathrm{c}}\left(\mathrm{HbA}_{1 c}\right.$; reference range, 4.3-5.8\%) was measured with a TOSHO automated glycohemoglobin analyzer (HLC-723G7; TOHSO Co., Tokyo, Japan). The value for $\mathrm{HbA}_{1 c}(\%)$ is estimated as an NGSP equivalent value (\%) calculated by the formula $\mathrm{HbA}_{1 \mathrm{c}}$ $(\%)=\mathrm{HbA}_{1 \mathrm{c}}$ (JDS) (\%) $+0.4 \%$, considering the relational expression of $\mathrm{HbA}_{1 \mathrm{c}}$ (JDS) (\%) measured by the previous Japanese standard substance and measurement methods and $\mathrm{HbA}_{1 \mathrm{c}}$ (NGSP) [21]. Plasma insulin was assayed by radioimmunoassay. Plasma insulin was assayed by chemiluminescent enzyme immunoassay.

Assessment of Brain Lesions. Silent cerebral infarction (SCI) was diagnosed using magnetic resonance imaging (MRI; GE Signa Horizon, 1.5 T; GE, Milwaukee, Wisc., USA). They were defined as irregular areas of high signal intensity $>3 \mathrm{~mm}$ in diameter on $\mathrm{T}_{2}$-weighted images, low-signal intensity areas on $\mathrm{T}_{1}$-weighted images, and areas of higher intensity than that of the cerebrospinal fluid in proton density images or fluid-attenuated inversion recovery images. Lesions $<3 \mathrm{~mm}$ in diameter or lesions with signal intensities similar to those of the cerebrospinal fluid in proton images and fluid-attenuated inversion recovery images were excluded because of the high possibility that they were enlarged perivascular spaces, even if they demonstrated high signals on $\mathrm{T}_{2}$-weighted images and low signals on $\mathrm{T}_{1}$-weighted images.

A modified rating scale was used to describe the different types of hyperintense signal abnormalities surrounding the ventricles and in the deep white matter [22]. Briefly, periventricular hyperintensity $(\mathrm{PVH})$ was graded as $0=$ absent, $1=$ 'caps' or pencil-thin lining, $2=$ smooth 'halo', and 3 = irregular PVH extending into the deep white matter. Separate deep white matter hyperintense lesions (WMLs) were rated as $0=$ absent, $1=$ punctate foci, $2=$ beginning confluence of foci, and $3=$ large confluent areas. 
Data Analysis

All data are presented means \pm SD. Multiple regression analysis was performed in order to search for an association between the covariants at baseline and the performance on cognitive function testing. The explanatory variables used in this study included age, gender (male $=1$, female $=0$ ), years of education, $\mathrm{HbA}_{1 c}$, serum insulin (log), the number of SCIs, and WML and PVH grading (0-3).

Multiple linear regression analyses were also performed to determine a longitudinal association between the covariants at baseline and changes between baseline and 3-year cognitive function tests. The objective variables included the score of each cognitive assessment or the change in scores from baseline to follow-up (subtracting the baseline score from the follow-up score), which was adjusted for age, gender, education, body mass index, GDS-15, mean blood pressure [diastolic blood pressure + (systolic blood pressure - diastolic blood pressure)/3], and T2DM duration. To analyze changes in scores, baseline score-based adjustments were also included.

\section{Results}

Table 1 summarizes the characteristics of the patients included in this study. The cognitive assessments were performed at baseline and 3 years later. Table 2 summarizes the scores of the cognitive assessments and the changes in scores from baseline to follow-up.

Higher plasma insulin levels correlated with a lower score in delayed word recall and a more cognitive response conflict in the Stroop test. Higher $\mathrm{HbA}_{1 \mathrm{c}}$ levels were also associated with a more cognitive response conflict in the Stroop performance (table 3 ).

Higher insulin levels at baseline were associated with decreased performance in the MMSE and DSS tests after 3 years. Higher $\mathrm{HbA}_{1 \mathrm{c}}$ levels at baseline were significantly associated with declines in the DSS and Stroop tests at the 3-year follow-up compared to baseline (table 4).

In the current study, we found no association between MRI-related factors (WMLs, PVLs, and number of SCIs) at baseline and follow-up (tables 3, 4). At the baseline assessment, which was adjusted for age, sex, T2DM duration, body mass index, and education, the number of SCIs was significantly associated with Stroop $(\beta=0.284, p=0.036)$ and DSS $(\beta=$ $0.248, p=0.048)$, and the degree of PVHs was associated with DSS $(\beta=-0.298, p=0.037)$. Further adjustments with mean blood pressure and depressive mood assessed by GDS-15 diminished the statistical significance of the association (table 3).

\section{Discussion}

In the current study, cross-sectional analyses indicated that higher plasma insulin levels correlated with a poorer Stroop test performance and poorer delayed word recall at baseline. Higher $\mathrm{HbA}_{1 \mathrm{c}}$ levels were also associated with a poorer Stroop test performance at baseline. Longitudinal analyses showed that higher insulin levels at baseline were associated with a decrease in MMSE and DSS scores after 3 years. Higher $\mathrm{HbA}_{1 c}$ levels at baseline correlated with a greater decrease in DSS and Stroop scores after 3 years. The results of brain MRI assessments were not related to cognitive performance in the current study. To our knowledge, no prospective studies have investigated the association between clinical factors (including imaging data) and cognitive decline in elderly diabetics with relatively preserved cognitive function.

Several cross-sectional studies have found that executive function/information processing speed, which was measured by the DSS and Stroop tests in the current study, is impaired 
Table 1. Patient characteristics

$\begin{array}{lc}\text { Patients, } \mathrm{n} & 55 \\ \text { Gender, males/females } & 23 / 32 \\ \text { Age, years } & 74.4 \pm 5.7 \\ \text { Body mass index } & 22.4 \pm 3.3 \\ \text { Duration of T2DM, years } & 17.2 \pm 9.3 \\ \text { Education, years } & 9.7 \pm 2.2 \\ \text { HbA }_{1 c} \text { \% } & 7.1 \pm 0.8 \\ \text { Total cholesterol, mg/dl } & 203.2 \pm 28.2 \\ \text { HDL cholesterol, mg/dl } & 53.7 \pm 15.1 \\ \text { Triglycerides, mg/dl } & 114.1 \pm 58.4 \\ \text { Immunoreactive insulin, } \mu \mathrm{U} / \mathrm{ml} & 7.6 \pm 7.3 \\ \text { Systolic BP, mm Hg } & 138.0 \pm 18.4 \\ \text { Diastolic BP, mm Hg } & 76.8 \pm 8.0 \\ \text { Presence of nephropathy, \% } & 25.4 \\ \text { Presence of retinopathy, \% } & 29.1 \\ \text { Presence of neuropathy, \% } & 14.5 \\ \text { Diabetic therapy (diet/OHA/insulin), } \mathrm{n} & 16 / 29 / 10 \\ \text { Antihypertensive treatment, \% } & 61.8 \\ \text { PVH (0-3) } & 0.9 \pm 0.9 \\ \text { WML (0-3) } & 0.9 \pm 0.8 \\ \text { SCIs, n } & 1.8 \pm 1.8\end{array}$

Means \pm SD. $\mathrm{HDL}=$ High-density lipoprotein; $\mathrm{BP}=$ blood pressure; $\mathrm{OHA}=$ oral hypoglycemic agent.

Table 2. The scores of the cognitive assessment tests

\begin{tabular}{lcc}
\hline Tests & Baseline assessment & Change in score \\
\hline MMSE & $26.7 \pm 2.2$ & $-2.6 \pm 3.5$ \\
DSS & $35.1 \pm 10.6$ & $-1.5 \pm 8.4$ \\
Stroop & $18.9 \pm 11.4$ & $3.0 \pm 8.4$ \\
Word recall (delayed) & $7.0 \pm 2.4$ & $-0.8 \pm 1.6$ \\
\hline
\end{tabular}

Means \pm SD. Range of scores: MMSE from 0 to 30, and word recall (delayed) from 0 to 10 .

Table 3. Linear regression analysis for baseline cognitive test scores with clinical variables

\begin{tabular}{|c|c|c|c|c|}
\hline & MMSE & DSS & $\begin{array}{l}\text { Word recall } \\
\text { (delayed) }\end{array}$ & Stroop \\
\hline Insulin (log) & $0.430(0.352)$ & $-3.197(0.139)$ & $-1.025(0.022)$ & $3.451(0.005)$ \\
\hline $\mathrm{HbA}_{1 \mathrm{c}}$ & $0.226(0.593)$ & $-3.124(0.112)$ & $-0.492(0.239)$ & $3.209(0.004)$ \\
\hline $\mathrm{PVH}$ & $0.138(0.640)$ & $-3.310(0.066)$ & $-0.006(0.988)$ & $0.789(0.471)$ \\
\hline WML & $0.248(0.529)$ & $-1.022(0.590)$ & $-0.174(0.657)$ & $-0.975(0.388)$ \\
\hline SCIs (n) & $-0.041(0.833)$ & $-1.261(0.163)$ & $-0.159(0.406)$ & $0.498(0.359)$ \\
\hline
\end{tabular}

$\mathrm{B}$ ( $\mathrm{p}$ value) for each cognitive assessment is shown. Adjusted for age, gender, education, body mass index, GDS-15, mean blood pressure, and T2DM duration. Statistically significant differences are italicized. 
Table 4. Linear regression analysis for changes in cognitive test scores with clinical variables

\begin{tabular}{|c|c|c|c|c|}
\hline & MMSE & DSS & $\begin{array}{l}\text { Word recall } \\
\text { (delayed) }\end{array}$ & Stroop \\
\hline Insulin (log) & $-1.839(0.012)$ & $-2.892(0.047)$ & $0.251(0.433)$ & $-0.797(0.724)$ \\
\hline $\mathrm{HbA}_{1 \mathrm{c}}$ & $-0.464(0.503)$ & $-2.734(0.040)$ & $-0.124(0.655)$ & $4.412(0.028)$ \\
\hline PVH & $0.078(0.902)$ & $-0.516(0.686)$ & $-0.119(0.630)$ & $-0.731(0.670)$ \\
\hline WML & $0.770(0.230)$ & $-0.029(0.982)$ & $0.206(0.417)$ & $0.541(0.761)$ \\
\hline SCIs (n) & $-0.247(0.434)$ & $0.177(0.776)$ & $0.094(0.454)$ & $0.600(0.483)$ \\
\hline
\end{tabular}

$B$ ( $p$ value) for each cognitive assessment is shown. Adjusted for age, gender, education, body mass index, GDS-15, mean blood pressure, T2DM duration, and baseline test score. Statistically significant differences are italicized.

in older diabetics [23-25]. A report on the inCHIANTI study has also demonstrated that insulin resistance is associated with impaired executive function in non-diabetic elderly [26]. In the current study, we found that higher insulin levels are associated with poorer Stroop test performance at baseline and a more significant decline in DSS scores at the 3-year followup. Higher $\mathrm{HbA}_{1 \mathrm{c}}$ levels were also associated with a poorer Stroop test performance at baseline and a more significant decline in DSS and Stroop test performance at the follow-up. In a recent systematic review [12], the reported processing speed was found to be significantly affected in $63 \%$ of published studies and attention was affected in $50 \%$. These observations suggest that executive function/information processing speed may be one of the cognitive domains responding to higher glucose and insulin levels. A recent follow-up study has demonstrated that patients with T2DM exhibited moderate decrements in information processing speed, attention, and executive functions in comparison to controls both at baseline and a 4-year follow-up examination [14].

A large cohort study, the ACCORD-MIND trial, has found that $\mathrm{HbA}_{1 \mathrm{c}}$ levels were crosssectionally associated with poorer performance in several cognitive function tests similar to those utilized in the current study [27]. Maggi et al. [13] have reported, based on a prospective study, that higher $\mathrm{HbA}_{1 \mathrm{c}}$ levels at baseline are associated with delayed verbal memory decline. Although the current results did not perfectly agree with the results of this study, the relevance of glycemic control in preserving cognitive function in elderly diabetics is strongly suggested. A recent prospective study by van den Berg et al. [14], however, has found that baseline $\mathrm{HbA}_{1 \mathrm{c}}$ levels have no effects on 5 cognitive domains. The reason for this discrepancy remains unclear at this point and should be further investigated. Their study included relatively younger subjects ( 65 years old at baseline) than ours ( 74 years old at baseline). It may be that older subjects are more vulnerable to diabetic metabolic abnormalities.

Many studies have shown that higher plasma insulin levels or insulin resistance are associated with cognitive dysfunction. Several studies have also reported the association between MMSE scores and insulin levels $[28,29]$. In the current study, we also noted an association between higher insulin levels and lower delayed word recall scores and poorer Stroop test performance at baseline. Higher insulin levels were also associated with declines in MMSE and DSS scores after 3 years. The mechanism by which insulin may impair cognition remains unclear; however, several hypotheses have been proposed to explain this phenomenon. Higher plasma insulin levels induce decreased insulin transport to the CNS, probably due to altered insulin transport mechanisms in the endothelial cells. The relative decrease in insulin levels within the brain may cause dysfunction of the central nervous system [30]. 
Fewer insulin signals are possibly associated with decreased cholinergic activity [31] and long-term potentiation in the hippocampus, which is critical to memory formation [32].

Several studies have demonstrated that white matter lesions are associated with cognitive processing speed assessed by DSS or similar tests [11,33,34], but in the current study, no MRI-derived indices were associated with any cognitive scores or declines in scores. Our previous study showed that WMLs and SCIs are factors contributing to cognitive impairment in diabetics [35], but in the current study, further adjustments with regard to blood pressure and depressive mood assessed by GDS-15 diminished the statistical significance of the association of ischemic lesions detected by MRI with cognitive test scores. The effects of ischemic small vessel lesions on cognition may occur, at least in part, via hypertension and depressive mood. Hypertension reportedly has a negative impact on cognition [12]. Depressive mood is also a factor that affects cognition, including processing speed [36]. The contribution of small vessel disease to depression has been scrutinized recently [37].

In the current study, higher $\mathrm{HbA}_{1 \mathrm{c}}$ and insulin levels were found to be associated with declines in select domains of neurocognitive assessments both at baseline and during the 3 -year follow-up. These results suggest that diabetic disease control is important for the preservation of cognitive function in elderly diabetic patients. Cognitive impairment may affect the self-care ability in these patients [38] and lead to a deterioration in metabolic control.

For further clarification of the effects of diabetic control on cognitive function, an interventional study is warranted.

A limitation of the current study was that MRI and clinical indices were only assessed at baseline. Therefore, effects of changes in glycemic control or insulin resistance and the progression of small vessel disease in the brain were not evaluated. Although no association between MRI findings at baseline and cognitive decline was observed, the present results do not indicate that progression of small vessel disease has no impact on declines in cognitive function.

Another potential limitation of the current study is that the participants were treated in a specialty clinic and their glycemic levels as well as other metabolic abnormalities were tightly controlled $(7.1 \pm 0.8 \%)$. Therefore this group may not be representative of the general diabetic population, which may bias the results.

Since the current study involved a relatively small number of patients and control subjects without diabetes were not included, our results should be confirmed by a prospective study including a larger patient cohort and non-diabetic controls.

\section{Conclusion}

In our cross-sectional analysis, higher plasma insulin levels at baseline were negatively correlated with performance in Stroop and delayed word recall tests. Higher $\mathrm{HbA}_{1 \mathrm{c}}$ levels were also negatively associated with performance in the Stroop test. Via longitudinal analysis of elderly T2DM patients, worse glycemic control, i.e. higher $\mathrm{HbA}_{1 \mathrm{c}}$ levels at baseline, was associated with a rapid decline in perceptual speed according to the DSS test and attention/ executive function according to the Stroop test. Higher insulin levels were associated with declines in MMSE and DSS performance. Diabetic disease control may be important for the preservation of cognitive function in elderly diabetics.

\section{Disclosure Statement}

The authors have no conflicts of interest to declare. 


\section{References}

1 Stewart R, Liolitsa D: Type 2 diabetes mellitus, cognitive impairment and dementia. Diabet Med 1999;16:93-112.

-2 Kodl CT, Seaquist ER: Cognitive dysfunction and diabetes mellitus. Endocr Rev 2008;29:494-511.

-3 Brownlee M: Biochemistry and molecular cell biology of diabetic complications. Nature 2001;414: $813-820$.

4 Valente T, Gella A, Fernàndez-Busquets X, Unzeta M, Durany N: Immunohistochemical analysis of human brain suggests pathological synergism of Alzheimer's disease and diabetes mellitus. Neurobiol Dis 2010;37:67-76.

5 Banks WA: Blood-brain barrier and energy balance. Obesity 2006;5:234-237.

-6 Tschritter O, Preissl H, Hennige AM, Stumvoll M, Porubska K, Frost R, Marx H, Klösel B, Lutzenberger W, Birbaumer N, Häring HU, Fritsche A: The cerebrocortical response to hyperinsulinemia is reduced in overweight humans: a magnetoencephalographic study. Proc Natl Acad Sci USA 2006; 103:12103-12108.

7 Young SE, Mainous AG 3rd, Carnemolla M: Hyperinsulinemia and cognitive decline in a middleaged cohort. Diabetes Care 2006;29:2688-2693.

8 Suzuki M, Umegaki H, Uno T, Oyun O, Mogi N, Maeno H, Yamanouchi K, Iguchi A, Sato Y: Association between insulin resistance and cognitive function in elderly diabetic patients. Geriatr Gerotr Int 2006;6:254-259.

-9 Luchsinger JA, Tang MX, Shea S, Mayeux R: Hyperinsulinemia and risk of Alzheimer disease. Neurology 2004;63:1187-1192.

-10 Stolk RP, Breteler MM, Ott A, Pols HA, Lamberts SW, Grobbee DE, Hofman A: The Rotterdam Study. Insulin and cognitive function in an elderly population. Diabetes Care 1997;20:792-795.

-11 Akisaki T, Sakurai T, Takata T, Umegaki H, Araki A, Mizuno S, Tanaka S, Ohashi Y, Iguchi A, Yokono $\mathrm{K}$, Ito $\mathrm{H}$ : Cognitive dysfunction associates with white matter hyperintensities and subcortical atrophy on magnetic resonance imaging of the elderly diabetes mellitus. Japanese elderly diabetes intervention trial (J-EDIT). Diabetes Metab Res Rev 2006;22:376-384.

-12 van den Berg E, Kloppenborg RP, Kessels RP, Kappelle LJ, Biessels GJ: Type 2 diabetes mellitus, hypertension, dyslipidemia and obesity: A systematic comparison of their impact on cognition. Biochim Biophys Acta 2009;1792:470-481.

-13 Maggi S, Limongi F, Noale M, Romanato G, Tonin P, Rozzini R, Scafato E, Crepaldi G; ILSA Study Group: Diabetes as a risk factor for cognitive decline in older patients. Dement Geriatr Cogn Disord 2009;27:24-33.

-14 van den Berg E, Reijmer YD, de Bresser J, Kessels RP, Kappelle LJ, Biessels GJ; Utrecht Diabetic Encephalopathy Study Group: A 4 year follow-up study of cognitive functioning in patients with type 2 diabetes mellitus. Diabetologia 2010;53:58-65.

-15 American Diabetes Association 2007. Standards of medical care in diabetes. Diabetes Care 2007; 30:S42-S47.

-16 Folstein MF, Folstein SE, McHugh PR: 'Mini-Mental State': a practical method of grading the cognitive function of patients or the clinician. J Psychiatr Res 1978;12:189-198.

-17 Mohs RC, Rosen WG, Davis KL: The Alzheimer's disease assessment scale: an instrument for assessing treatment efficacy. Psychopharmacol Bull 1983;19:448-450.

18 Shinagawa F, Kobayashi S, Fujita K, Mekawa H: Japanese Manual of the Wechsler Adult Intelligence Scale-Revised. Nihon-bunka-kagaku-sya, Tokyo, 1990, pp 115-118.

-19 Stroop JR: Studies of interference in serial verbal reactions. J Exp Psychol 1935;18:643-662.

20 Yesavage JA: The use of self-rating depression scales in the elderly; in Poon LW (ed): Clinical Memory Assessment of Older Adults. American Psychological Association, Washington DC, 1986.

21 The Committee of Japan Diabetes Society on the diagnostic criteria of diabetes mellitus. Report of the Committee on the classification and diagnostic criteria of diabetes mellitus. J Jpn Diabetes Soc 2010;53:450-467.

-22 Fazekas F, Chawluk JB, Alavi A, Hurtig HI, Zimmerman RA: MR signal abnormalities at $1.5 \mathrm{~T}$ in Alzheimer's dementia and normal aging. AJR Am J Roentgenol 1987;149:351-356. 
-23 van den Berg E, Dekker JM, Nijpels G, Kessels RP, Kappelle LJ, de Haan EH, Heine RJ, Stehouwer CD, Biessels GJ: Cognitive functioning in elderly persons with type 2 diabetes and metabolic syndrome: the Hoorn study. Dement Geriatr Cogn Disord 2008;26:261-269.

-24 Qiu WQ, Price LL, Hibberd P, Buell J, Collins L, Leins D, Mwamburi DM, Rosenberg I, Smaldone L, Scott TM, Siegel RD, Summergrad P, Sun X, Wagner C, Wang L, Yee J, Tucker KL, Folstein M: Executive dysfunction in homebound older people with diabetes mellitus. J Am Geriatr Soc 2006;54: 496-501.

-25 Fischer AL, de Frias CM, Yeung SE, Dixon RA: Short-term longitudinal trends in cognitive performance in older adults with type 2 diabetes. J Clin Exp Neuropsychol 2009;31:809-822.

-26 Abbatecola AM, Paolisso G, Lamponi M, Bandinelli S, Lauretani F, Launer L, Ferrucci L: Insulin resistance and executive dysfunction in older persons. J Am Geriatr Soc 2004;52:1713-1718.

-27 Cukierman-Yaffe T, Gerstein HC, Williamson JD, Lazar RM, Lovato L, Miller ME, Coker LH, Murray A, Sullivan MD, Marcovina SM, Launer LJ: Relationship between baseline glycemic control and cognitive function in individuals with type 2 diabetes and other cardiovascular risk factors: the action to control cardiovascular risk in diabetes-memory in diabetes (ACCORD-MIND) trial; Action to Control Cardiovascular Risk in Diabetes-Memory in Diabetes (ACCORD-MIND) Investigators. Diabetes Care 2009;32:221-226.

-28 Vanhanen M, Koivisto K, Kuusisto J, Mykkänen L, Helkala EL, Hänninen T, Riekkinen P Sr, Soininen H, Laakso M: Cognitive function in an elderly population with persistent impaired glucose tolerance. Diabetes Care 1998;21:398-402.

-29 Geroldi C, Frisoni GB, Paolisso G, Bandinelli S, Lamponi M, Abbatecola AM, Zanetti O, Guralnik JM, Ferrucci L: Insulin resistance in cognitive impairment: the inCHIANTI study. Arch Neurol 2005;62:1067-1072.

-30 Hallschmid M, Schultes B: Central nervous insulin resistance: a promising target in the treatment of metabolic and cognitive disorders? Diabetologia 2009;52:2264-2269.

-31 Welsh B, Wecker L: Effects of streptozotocin-induced diabetes on acetylcholine metabolism in rat brain. Neurochem Res 1991;16:453-460.

- 32 Kamal A, Biessels GJ, Urban IJ, Gispen WH: Hippocampal synaptic plasticity in streptozotocin-diabetic rats: impairment of long-term potentiation and facilitation of long-term depression. Neuroscience 1999;90:737-745.

- 33 Jokinen H, Kalska H, Ylikoski R, Madureira S, Verdelho A, van Der Flier WM, Scheltens P, Barkhof F, Visser MC, Fazekas F, Schmidt R, O’Brien J, Waldemar G, Wallin A, Chabriat H, Pantoni L, Inzitari D, Erkinjuntti T; LADIS group: Longitudinal cognitive decline in subcortical ischemic vascular disease - the LADIS Study. Cerebrovasc Dis 2009;27:384-391.

-34 Turken A, Whitfield-Gabrieli S, Bammer R, Baldo JV, Dronkers NF, Gabrieli JD: Cognitive processing speed and the structure of white matter pathways: convergent evidence from normal variation and lesion studies. Neuroimage 2008;42:1032-1044.

- 35 Umegaki H, Kawamura T, Mogi N, Umemura T, Kanai A, Sano T: Glucose control levels, ischaemic brain lesions, and hyperinsulinaemia were associated with cognitive dysfunction in diabetic elderly. Age Ageing 2008;37:458-461.

-36 Herrmann LL, Goodwin GM, Ebmeier KP: The cognitive neuropsychology of depression in the elderly. Psychol Med 2007;37:1693-1702.

- 37 Santos M, Kövari E, Hof PR, Gold G, Bouras C, Giannakopoulos P: The impact of vascular burden on late-life depression. Brain Res Rev 2009;62:19-32.

-38 Compeán-Ortiz LG, Gallegos EC, Gonzalez-Gonzalez JG, Gomez-Meza MV, Therrien B, Salazar BC: Cognitive performance associated with self-care activities in Mexican adults with type 2 diabetes. Diabetes Educ 2010;36:268-275. 